\title{
German Animal Welfare Act in breach with Directive 2010/63/EU
}

\author{
Summary \\ The German Federal Administrative Court recently announced an order (finalized on January 20, 2014) on \\ the neurobiological experiments on primate brains of Prof. Kreiter at the University of Bremen. With this \\ order, a preceding court decision by the Higher Administrative Court of Bremen was established as final \\ and absolute and the last glimmer of hope to end the suffering of the primates in Bremen was extinguished. \\ The court decision had claimed the experiments to be ethically justified. The Federal Administrative Court \\ upheld the court decision and issued the order on the grounds that due to the phrasing of both the former \\ and the current German Animal Welfare Act, authorities had no entitlement to assess the ethical justifica- \\ tion of an experiment, but were obliged to approve an application if all formalities were complied with. The \\ impact the order will have on the authorization of animal experiments and testing in Germany caused an \\ outrage in the animal welfare community.
}

\section{Introduction}

After the order of the German Federal Administrative Court ${ }^{1}$ became public, the German Animal Welfare Federation took immediate action and both addressed the competent German Federal Minister, demanding a revision of the German Animal Welfare Act, and appealed to its own members to withdraw their participation in committees advising competent authorities on the evaluation of proposed projects involving animal experiments in Germany (Beratende Kommissionen; "ethical review committees"). But the curtailment of the right to evaluate the ethical justification of a project involving animal experiments for authorization by the competent authorities is not the only failure of the German Federal Government to transpose Directive 2010/63/EU correctly. Directive 2010/63/EU ${ }^{2}$ of the European Parliament and of the Council on the protection of animals used for scientific purposes was transposed in the third amendment of the German Animal Welfare Act (Tierschutzgesetz; TierSchG) of July $4,2013^{3}$ and the resulting new Regulation on the protection of animals used for scientific purposes of August $1,2013^{4}$. In cooperation with the German Judicial Association for Animal Welfare Law (Deutsche Juristische Gesellschaft für Tierschutzrecht, DJGT), we detailed the shortcomings of the German transposition of Directive 2010/63/EU in an expert opinion and filed a complaint against Germany to the European Commission. We demand that Germany is held accountable for these shortcomings if the German Federal Government does not initiate a revision of the German Animal Welfare Act. In this article, we would like to highlight the shortcomings of the Ger- man Animal Welfare Act in terms of the correct transposition of Directive 2010/63/EU and explain the reasons for our decision to end our participation in ethical review committees.

\section{Project evaluation by the competent authority (Art. 36(2) and Art. 38(2) of Directive 2010/63/EU)}

According to Directive 2010/63/EU, scientific procedures involving animal use may only be performed if the competent authority's evaluation of the project application has a positive outcome (Art. 36(2)). The project evaluation described in Directive 2010/63/EU includes, among other things, the assessment of the objectives, the predicted scientific benefits (Art. 38(2)a), the assessment of the compliance with the requirement of replacement, reduction, and refinement (Art. 38(2)b) and a harmbenefit analysis of the project (Rec. 39, Art. 38(2)d). The latter is to assess whether the harm inflicted on the animals in terms of suffering, pain, and distress is justified by the expected outcome of the project, taking into account ethical considerations, and if the expected results may ultimately be of benefit for human beings. The project evaluation by the competent authority shall be impartial and independent of those involved in the study (Rec. 39, Art. 38(4)).

With regard to two central aspects of the requirements for an authorization laid down in Directive 2010/63/EU - the indispensability (i.e., among other things the compliance with the requirement for replacement, reduction, and refinement of animal use in scientific procedures according to the 3 Rs principle)

\footnotetext{
Received April 1, 2014; http://dx.doi.org/10.14573/altex.1404011

1 Beschluss des Bundesverwaltungsgerichtes, BVerwG 3 B 29.13, 20.01.2014

2 European Union (2010), Directive 2010/63/EU of the European Parliament and of the Council of 22 September 2010 on the protection of animals used for scientific purposes

3 Drittes Gesetz zur Änderung des Tierschutzgesetzes vom 4. Juli 2013, BGBI. 2013 part I Nr. 36, pp.2182-2196

4 Verordnung zum Schutz von zu Versuchszwecken oder zu anderen wissenschaftlichen Zwecken verwendeten Tieren

Tierschutz-Versuchstierverordnung - TierSchVersV), 1.8.2013, BGBI. 2013 part I Nr. 47, pp. 3125-3145
} 
and the assessment of ethical considerations (the harm-benefit analysis according to Art. 38(2d) - Art. 8(1), sentence 2, no. 1 of the German Animal Welfare Act states that a scientific procedure involving animal use has to be authorized if the applicant presents the indispensability of the procedure to be scientifically proven. Therefore, the objectives for an impartial and independent assessment by the competent authority have not been transposed correctly in the German Animal Welfare Act.

In addition, Directive 2010/63/EU uses the term "justified" in combination with the proof of indispensability in Art. 38. This is not correctly translated into German law - here "justified" was changed to "if presented to be scientifically proven", which does not have the same meaning ("gerechtfertigt" vs. "wissenschaftlich begründet") in the German language.

This "downgrading" of the phrasing in Art. 8(1), sentence 2, no. 1 TierSchG (authorization "has to be granted", if the compliance with the measures is "presented to be scientifically proven") runs the predictable risk that authorities and courts will not see the possibility to evaluate the indispensability and ethical tenability impartially and independently from the assessment done by the applicant. The Higher Administrative Court of Bremen has interpreted Art. 8(3), no. 1, TierSchG (prior to its revision in 2013) to not allow authorities and courts to impartially and independently examine either the availability of possible replacement and reduction methods or the scientific benefit of the use of animals in a procedure. With respect to these authorization requirements the law stipulates a downgrading of the control measures towards a mere plausibility check. Authorities and courts are therefore restricted to examine whether the information submitted by the applicant is plausible and conclusive. In contrast, they are not allowed to undertake their own investigations, to consider facts that have not been presented by the applicant, or to request expertise to assist them in their assessment. Also, they are not permitted to use criteria other than those that were used by and considered to be adequate by the applicant ${ }^{5}$.

The order of the Federal Administrative Court of January 20, 2014 comes to the same conclusion. According to this order, authorities have to grant authorization of a project involving animal experiments if the applicant has, among other things, presented the indispensability and ethical tenability of the case to be scientifically proven. That makes it clear that the phrasing used in Art. 8(1), sentence 2, no. 2, TierSchG does not reflect the requirements laid down in Art. 38(2) and Art. 36(2) of Directive 2010/63/EU. Therefore, in Germany, the project evaluation cannot be conducted impartially and independently of those involved in the study contrary to Rec. 39 and Art. 38(4) of the EU Directive. Instead, the information given by the applicant may not be challenged by the authorities. The same applies to the question of whether the submitted project is indispensable or whether replacement and reduction methods are available, which the authorities could claim as an aim overriding the applicant's aim to conduct the experiments. Therefore, one of the main objectives of the EU Directive has been neglected.

\section{Animal experiments for higher education or training (Art. 5f, Directive 2010/63/EU)}

The scope of Directive 2010/63/EU also covers procedures involving animals used in higher education and training for the acquisition, maintenance, or improvement of vocational skills. Before permission to conduct these is granted, the competent authority's project evaluation must have a positive outcome. It is not permitted to apply the simplified administrative procedure (Art. 42, Directive 2010/63/EU) here. Instead, a full authorization process is mandatory.

According to Art 8a(1), no. 4, TierSchG, procedures involving animals for purposes of education, training, and advanced vocational training with methods that have already been established do not need to be authorized (in principle, an authorization is foreseen to be mandatory for all scientific procedures involving animals in Art. 8(1), sentence 1), but only have to meet the requirements of the simplified administrative procedure (the socalled "Anzeigeverfahren": "notification procedure" in accordance with the German Animal Welfare Act). As a consequence, the applicant who wants to conduct such experiments does not need authorization by the competent authority. It is sufficient to notify the competent authority of the planned project. If the competent authority does not react within 20 working days of the notification, the applicant can start the procedure.

In our point of view, the German legislator has violated Art. 36 (2) of Directive 2010/63/EU by allowing the performance of scientific procedures involving animals without prior authorization in the field of higher education. In accordance with the requirements laid down in Directive 2010/63/EU, EU member states may only make use of the simplified administrative procedure for projects classified as "non-recovery," "mild" or "moderate" and not using non-human primates that are necessary to satisfy regulatory requirements, or which use animals for production or diagnostic purposes with established methods. Projects for higher education or training are not covered by these exemptions of the authorization procedure.

This assessment also is shared by the Federal Council of Germany (cf. its resolution of June 7, 2013, BR-Printed matter 431/13, translated by the authors of this comment: "The Federal Council of Germany advises the Federal Government to assign especially animal experiments for the purpose of education, training, and advanced vocational training to the authorization procedure of Art 8(1) of the future TierSchG to meet the EU Directive. [...] Art. 42 of EU Directive 2010/63/EU does not allow the "simplified administrative procedure" for this purpose. Animal experiments for education, training, and advanced vocational training have to be mandatorily authorized.")

The intention of Art. 36 of Directive 2010/63/EU is that no project is carried out unless a favorable project evaluation by the competent authority has been received. This aim is infringed by Art. $8 \mathrm{a}(1)$, no. 4, TierSchG. This is unacceptable bearing in mind that under the scope of education many animals are used in experiments every year (In Germany, 62.186 animals were

5 Oberverwaltungsgericht Bremen (2012), Urteil vom 11. Dezember 2012, 1 A 180/10 juris Rn 143, 145 
used in scientific procedures for educational purposes in 2012) and - as these procedures are part of the education of future generations of lab assistants, scientists, doctors and veterinarians - it should be carried out in an exemplary manner.

In our view it has to be made clear that according to Directive 2010/63/EU all procedures using animals for education, training, and advanced vocational training have to undergo the full authorization procedure; this also applies for Germany.

\section{Simplified administrative procedure (Art. 42, Directive 2010/63/EU)}

The legislator of the European Union explicitly states in Art. 42(4) that scientific procedures involving animals that comply with the requirements for the simplified administrative procedure have to be permitted by the competent authority as well.

In accordance with Art. 8a(1), no. 1-3, TierSchG and Art. 36(2), TierSchVersV no such permission by the competent authority is required. Applicants only have to notify the competent authority that they plan to conduct a scientific procedure that complies with the requirements for the simplified administrative procedure. They can initiate their experiments 20 working days after submitting the notification if the competent authority does not actively react. No further decision ("permit") by the competent authority is needed.

Therefore, the "notification procedure" ("Anzeigeverfahren") for regulatory animal testing and procedures for production or diagnostic purposes as provided in Art. 8a(1), no. 1-3, TierSchG is not consistent with the simplified administrative procedure laid down in Art. 42(1), Directive 2010/63/EU for specific procedures.

Permission to conduct a procedure compliant with the requirements of Art. 42(4) of Directive 2010/63/EU implies a positive action by the competent authority. This positive action means an act of volition by the competent authority. An office holder has to be in charge of this volitional act and it has to become clear that the competent authority has evaluated the project application in terms of its indispensability (i.e., compliance with the requirement of replacement, reduction, and refinement) and ethical tenability (the harm-benefit analysis according to Art. 38 (2)d of the Directive 2010/63/EU) and that this project evaluation had a positive outcome (in accordance with the requirements laid down in Art. 36(2)). In addition, concerning Art. 42 of Directive 2010/63/EU, it is clarified in a document on the interpretation of specific articles of Directive 2010/63/EU issued by the European Commission ${ }^{6}$ that it is expected that prior to conducting procedures involving animals that fall under the simplified administrative procedure, the competent authority has done a proper project evaluation with a positive outcome. However, there is no specific document for the decision and it is not bound to compliance with specific formalities.

In contrast, in accordance with Art. 8a(1), no. 1-3, TierSchG and Art. 36(2), TierSchVersV, it is already sufficient if the rele- vant authority remains silent for 20 working days after receiving the notification. Thereafter the applicant can start to conduct the scientific procedure. However, mere silence does not fulfil the prerequisite of permission. Any such consent requires action by the office holder in terms of a statement. It needs to become clear from the statement that the project has been evaluated and that this evaluation had a positive outcome as well as that the office holder takes responsibility for the evaluation (cf. also the reference to Art. 42(4) and Art. 44(3-5), Directive 201/63/EU: the respective articles deal with possible amendment, renewal, and withdrawal of a project authorization that was already granted, ergo a volitional act by the competent authority. In this case, the volitional act comprises a statement. As a consequence, this statement is in excess of the mere silence that is accepted to be sufficient in Art. 8a(1), no. 1-3, TierSchG).

In contrast to this, the "fictional" approval via mere silence already eventuates if the competent authority has not been able to examine the applicant's notification with regards to contents yet, e.g., due to work overload.

Hence Art. 8a(1), TierSchG falls short of the aim of Directive 2010/63/EU as expressed in Art. 36(2) and Art. 42 that scientific procedures involving animals should not be conducted without previous approval by the authority including a positive outcome of the project evaluation.

In our opinion it has to be clarified that scientific procedures involving animals which are subject to the simplified administrative procedure may only be conducted if prior to that the competent authority has issued a notification that includes the outcome of its project evaluation.

\section{Pain, suffering, and distress of animals used in scientific procedures (Art. 3(1))}

Directive 2010/63/EU defines a procedure as "any use, invasive or non-invasive, of an animal for experimental or other scientific purposes, with known or unknown outcome, or educational purposes, which may cause the animal a level of pain, suffering, distress or lasting harm equivalent to, or higher than, that caused by the introduction of a needle in accordance with good veterinary practice." Due to linguistic differences in the meaning of the word "distress" in English and German, the official German version of Directive 2010/63/EU ${ }^{7}$ explicitly lists "fear" ("Ängste") as a separate parameter in addition to pain, suffering and distress.

The German Animal Welfare Act only lists pain, suffering, and distress as possible damages for animals used in scientific procedures (Art. 7(1), sentence 2, no. 1, lit. a and following paragraphs). Even though it is possible to opine that "fear" could be subsumed under the term "distress", this is only true for the English language. In German, there is no such analogy of the two terms (i.e., in German, the term "Leiden" does not comprise the term "Ängste"). Fear especially incorporates psychological and emotional strain of the animal and is not comprised within

\footnotetext{
6 http://ec.europa.eu/environment/chemicals/lab_animals/pdf/qa.pdf

7 http://eur-lex.europa.eu/legal-content/DE/TXT/PDF/?uri=CELEX:32010L0063\&qid=1396427492913\&from=EN
} 
the other three terms (pain, suffering, and distress). In our opinion it is therefore necessary and reasonable, also in terms of the predictability of legal decisions, to clarify that inflicting fear on animals is also subject to the same regulations as inflicting pain and (other) suffering. Without this clarification there is the substantial risk that inflicting fear on the animals will be taken less seriously than and weighted lower in comparison to inducing (other) suffering.

With this failure to correctly transpose the requirements of Directive 2010/63/EU the German Animal Welfare Act once again falls short of the animal welfare standard that is legally binding for all EU member states.

In our opinion the German legislator has to incorporate the term "fear" ("Ängste") as a separate parameter of the possible damages for animals used in scientific procedures into the Animal Welfare Act to fulfil the requirements of Art. 3(1) of Directive 2010/63/EU.

\section{Discussion}

In Germany, representatives of animal welfare organizations have struggled with the strain of moral conflicts ever since they decided to participate in "ethical review committees" to advise competent authorities in the process of authorization of scientific procedures involving animals. In the time since the decision to participate was made, i.e., when the ethical review committees were set up for the first time after the revision of the German Animal Welfare Act in 1986, many of the original motives for participating seem to have been buried in oblivion. These motives included inter alia the intention to scrutinize the authorization process, but the aim that was paramount to all others was to use this opportunity to act as a counterbalance against the scientists' interests and to help to prevent animal experiments from being conducted.

Contrary to general opinion, it is not the intention and can never be the task of representatives of animal welfare organizations to see to the proper implementation of refinement of animal experiments and testing. Of course, refinement is absolutely essential as long as animal experiments and testing are conducted. It is understood that it is still a big success in terms of animal welfare if the number of animals used in a procedure is reduced or if anesthetics are used to ease the pain inflicted on the animals, etc. But the implementation of all available refinement measures is not only required by law, but should also be left in the capable hands of laboratory animal scientists.

What made us even consider and keep up the participation in the ethical review committees; however, were the high hopes to act as the animals' advocates and save them from being downgraded to measuring instruments and being used in experiments. But we were frustrated again and again. In the beginning, we were told that it was due to the freedom of research that we could not prevent animal experiments from being conducted. When animal welfare finally was included as a national objective in the
German Basic Law in 2002, we dared to hope that with this we now had a tool to stop animal experiments. But what we have learned instead is that nothing has changed. The lion's share of scientific procedures involving animals is still authorized with almost no chance to prevent this (Kolar and Ruhdel, 2007); unfortunately, this criticism is still current. Not to forget that the participation of representatives of animal welfare organizations in the ethical review committees is often misused by applicants to state that their projects have been evaluated and concluded to be ethically justifiable by animal welfare activists.

The German Federal Government had another opportunity to set things straight in 2013 with the national transposition of Directive 2010/63/EU. But not even the resulting revision of the German Animal Welfare Act was used to clarify and clean up the well-known problems of the authorization process. With the order of the German Federal Administrative Court, this sad chapter in the history of the German Animal Welfare Act now seems to have been closed for years to come. We cannot accept this and we do not want to act as servants of the execution of a law that does not live up to its title and is falling short of the necessary measures to protect animals from pain, harm, fear, and distress any longer. Therefore, we had to make a mark by appealing to our members to end their participation in the ethical review committees. Even though we know that with our decision there is no one left in the ethical review committees who will argue in favor of the animals and against animal experiments, we need to draw public attention to the problems that we have experienced for a long time. Our demand now is that the German Federal Government acts immediately and initiates a revision of the German Animal Welfare Act so that all of the shortcomings we addressed in our expert opinion and in this article will be corrected as soon as possible. It remains to be seen what outcome the complaint we filed against Germany will have. Let us hope for the best.

\section{References}

Kolar, R. and Ruhdel, I. (2007). A survey concerning the work of ethics committees and licensing authorities for animal experiments in Germany. ALTEX 24, 326-334.

\author{
Irmela Ruhdel $^{1 *}$, Christoph Maisack ${ }^{2}$, and Kristina Wagner ${ }^{1}$ \\ ${ }^{1}$ German Animal Welfare Federation / Animal Welfare \\ Academy, Neubiberg, Germany; ${ }^{2}$ German Judicial Association \\ for Animal Welfare Law, Berlin, Germany \\ *Corresponding author: \\ Irmela Ruhdel \\ Animal Welfare Academy \\ Spechtstr. 1 \\ 85579 Neubiberg \\ Germany \\ e-mail: irmela.ruhdel@tierschutzakademie.de
}

